\title{
CONSERVAÇÃO DE PIMENTÃO VERDE MINIMAMENTE PROCESSADO ACONDICIONADO EM DIFERENTES EMBALAGENS PLÁSTICAS ${ }^{1}$
}

\author{
Brígida Monteiro Vilas Boas², Heloísa Helena de Siqueira ${ }^{3}$, \\ Suzana Chitarra Leme ${ }^{3}$, Luiz Carlos de Oliveira Lima ${ }^{3}$, Tatielle Custódio Alves ${ }^{3}$
}

\begin{abstract}
CONSERVATION OF MINIMALLY PROCESSED GREEN PEPPER CONDITIONED IN DIFFERENT PLASTIC PACKAGES
\end{abstract}

Minimal processing of vegetables adds value to the final product for increasing its convenience and reducing the time to prepare meals. This study aimed to evaluate the conservation of minimally processed green peppers 'Konan R', sliced and conditioned in different plastic packages. The fruits were selected, washed, and sanitized in a sodium hypochlorite solution (200 $\left.\mathrm{mg} \mathrm{L}^{-1}\right)$, for 15 minutes. Their slices $(1.0 \mathrm{~cm}$ thickness) were sanitized in a sodium hypochlorite solution $\left(50 \mathrm{mg} \mathrm{L}^{-1}\right)$, for 5 minutes, and then conditioned in: 1) expanded polystyrene trays, covered with polyvinyl chloride film (PVC) $0.014 \mathrm{~mm}$; 2 ) rigid polypropylene (PP) packages, with lid made of the same polymer; 3) bioriented polypropylene (BOPP) $0.060 \mathrm{~mm}$ plastic bags. The product was stored at $5 \pm 0.1^{\circ} \mathrm{C}$ and $\mathrm{RH}$ of $95 \pm 1 \%$, for 6 days. The following analyses were performed every 2 days: mass loss, titratable acidity and ascorbic acid contents, $\mathrm{pH}$, color (expressed in $\mathrm{L}^{*}$ and $\mathrm{a}^{*}$ values), and slices vigor. The plastic packages and storage time did not affect the $\mathrm{pH}, \mathrm{L}^{*}$ value, and slices vigor. The titratable acidity contents and $\mathrm{a}^{*}$ value were affected by storage time. The polystyrene tray covered with PVC film led to greater mass loss and lower ascorbic acid content, in slices of green peppers stored at $5^{\circ} \mathrm{C}$, for 6 days. Thus, the PP package and the BOPP plastic bag are preferable to condition minimally processed green pepper.

KEY-WORDS: Capsicum annuum L.; refrigeration; mass loss.

\section{INTRODUÇÃO}

O pimentão é uma baga oca, de formato cônico, cilíndrico ou cúbico. Apresenta coloração vermelha, amarela ou outras cores, quando maduro. A maior parte da produção comercializada tem sido de frutos colhidos verdes, porém, a demanda

\section{RESUMO}

O processamento mínimo de hortaliças agrega valor ao produto final, pelo fato de aumentar a sua conveniência e reduzir o tempo de preparo das refeições. O objetivo deste trabalho foi avaliar a conservação de pimentões verdes 'Konan R' minimamente processados, no formato de rodelas, e acondicionados em diferentes embalagens plásticas. Os pimentões foram selecionados, lavados e sanificados em solução de hipoclorito de sódio $\left(200 \mathrm{mg} \mathrm{L}^{-1}\right)$, por 15 minutos. As rodelas (1,0 cm de largura) foram sanificadas em solução de hipoclorito de sódio ( $50 \mathrm{mg} \mathrm{L}^{-1}$ ), por 5 minutos, e, em seguida, acondicionadas em: 1) bandeja de poliestireno expandido, envolta com filme de policloreto de vinila (PVC) $0,014 \mathrm{~mm}$; 2 ) embalagem rígida de polipropileno (PP), com tampa do mesmo polímero; 3) saco plástico de polipropileno biorientado (BOPP) 0,060 $\mathrm{mm}$. O produto foi armazenado a $5 \pm 0,1^{\circ} \mathrm{C}$ e $95 \pm 1 \%$ UR, por 6 dias. As seguintes análises foram realizadas a cada 2 dias: perda de massa, teores de acidez titulável e de ácido ascórbico, pH, coloração (expressa em valores $\mathrm{L}^{*}$ e $\mathrm{a}^{*}$ ) e firmeza. As embalagens plásticas e o tempo de armazenamento não alteraram o $\mathrm{pH}$, o valor $\mathrm{L}^{*}$ e a firmeza das rodelas. Os teores de acidez titulável e o valor $a^{*}$ foram afetados pelo tempo de armazenamento. A bandeja de poliestireno envolta com filme PVC determinou maior perda de massa e menor teor de ácido ascórbico, nas rodelas de pimentão armazenadas a $5^{\circ} \mathrm{C}$, por 6 dias. Assim, a embalagem rígida de PP e o saco plástico de BOPP são preferíveis para acondicionar pimentão verde minimamente processado.

PALAVRAS-CHAVE: Capsicum annuum L.; refrigeração; perda de massa.

por frutos vermelhos, maduros, vem aumentando (Filgueira 2007).

O pimentão é uma das hortaliças mais ricas em vitamina $\mathrm{C}$ e, quando maduro, é excelente fonte de vitamina A. Também é fonte de cálcio, fósforo e ferro, além de possuir poucas calorias (Luengo et al. 2000, Lana et al. 2011). Sua comercialização é

1. Trabalho recebido em set./2011 e aceito para publicação em fev./2012 (n registro: PAT 15629).

2. Instituto Federal de Educação, Ciência e Tecnologia do Sul de Minas Gerais, Campus Machado, Machado, MG, Brasil.

E-mail: brigida@mch.ifsuldeminas.edu.br.

3. Universidade Federal de Lavras, Departamento de Ciência dos Alimentos, Lavras, MG, Brasil. E-mails: heloisa.elias@yahoo.com.br, suchitarra@hotmail.com, lcolima@ufla.br, tatiellecustodio@yahoo.com.br. 
realizada com os frutos in natura, porém, já existe a opção de produtos minimamente processados (Evangelista et al. 2008).

Frutas e hortaliças minimamente processadas são vegetais que passaram por alterações físicas, sendo descascados e/ou picados, e/ou torneados, e/ou ralados, dentre outros processos, mas mantidos em estado fresco e metabolicamente ativos. O sucesso da técnica deve-se à agregação de valor aos produtos primários colhidos e ao fato de serem comercializados prontos para o consumo. Dentre os fatores indispensáveis para assegurar a qualidade dos produtos minimamente processados, destacam-se a embalagem e a temperatura de armazenamento (Moretti 2007).

As hortaliças minimamente processadas são mais perecíveis do que seus similares intactos, o que se traduz em maior perda d'água, maior taxa respiratória e alterações bioquímicas e fisiológicas mais intensas. Portanto, as embalagens têm função de minimizar ou retardar estes eventos, prolongando ao máximo a sua vida útil. A seleção de filmes com certas propriedades de permeabilidade a gases, a uma dada temperatura, é fundamental para o estabelecimento da atmosfera adequada ao metabolismo do vegetal, no interior da embalagem. A espessura é, também, fator de controle de permeabilidade (Moretti \& Puschmann 2006).

Muitos tipos de filme e embalagem estão disponíveis no mercado, para uso em produtos minimamente processados. As embalagens podem ser bandejas de plástico ou poliestireno (isopor), com tampa ou envoltas em filmes de plástico, e sacos de plástico de diferentes composições (Soares \& Geraldine 2007).

Segundo Özkan et al. (2004), o teor de vitamina $\mathrm{C}$ constitui-se em importante fator para o controle de qualidade de alimentos, e é usado como parâmetro de qualidade nutricional, por ser mais sensível à degradação, durante o processamento e armazenamento, em relação a outros nutrientes. Maia et al. (2008), ao estudarem o teor de vitamina $\mathrm{C}$ em hortaliças minimamente processadas e in natura, observaram que o teor desta vitamina no pimentão in natura (130 mg de ácido ascórbico por $100 \mathrm{~g}$ ) foi maior que o do minimamente processado $(90 \mathrm{mg}$ de ácido ascórbico por $100 \mathrm{~g}$ ), correspondente a uma redução de $31 \%$.

Diante do exposto, o objetivo deste trabalho foi avaliar a conservação de pimentões verdes minimamente processados, no formato de rodelas, e acondicionados em diferentes embalagens plásticas.

\section{MATERIAL E MÉTODOS}

Pimentões 'Konan $\mathrm{R}$ ' resultantes de cultivo convencional, no estádio de maturação completamente verde, com base na coloração dos frutos (Albuquerque et al. 2009), oriundos do município de Ijaci (MG), foram transportados para o Laboratório de Pós-Colheita de Frutas e Hortaliças do Departamento de Ciência dos Alimentos da Universidade Federal de Lavras, em Lavras (MG), em 2007, onde foram selecionados quanto à presença de injúrias e defeitos. Os frutos foram lavados em água corrente, com detergente neutro, e, em seguida, sanitizados em solução de hipoclorito de sódio $\left(200 \mathrm{mg} \mathrm{L}^{-1}\right)$, por 15 minutos, e secos a $18^{\circ} \mathrm{C}$, naturalmente. Os pimentões foram cortados transversalmente, no formato de rodela com largura média de $1,0 \mathrm{~cm}$, com o auxílio de facas afiadas de aço inoxidável. As sementes e a região peduncular foram removidas. As rodelas foram sanitizadas em solução de hipoclorito de sódio (50 $\left.\mathrm{mg} \mathrm{L}^{-1}\right)$, por 5 minutos, e colocadas em peneiras plásticas, por 2 minutos, para a eliminação do excesso de líquido acumulado.

As rodelas (em média $150 \mathrm{~g}$ ) foram acondicionadas em diferentes embalagens plásticas: 1) bandeja de poliestireno expandido $(21 \mathrm{~cm} \mathrm{x} 14 \mathrm{~cm} \mathrm{x} 2 \mathrm{~cm})$, envolta manualmente com filme flexível de policloreto de vinila (PVC), com $0,014 \mathrm{~mm}$ de espessura e taxas de permeabilidade ao $\mathrm{O}_{2}$ e vapor d'água de $414,22 \% \mathrm{~m}^{-2}$ dia $^{-1}$ e $123,39 \mathrm{~g} \mathrm{~m}^{-2}$ dia $^{-1}$, respectivamente, sob condições normais de temperatura e pressão (temperatura de $23^{\circ} \mathrm{C}$ e pressão de $1 \mathrm{~atm}$ ); 2) embalagem rígida de polipropileno (PP) $(15 \mathrm{~cm} \mathrm{x}$

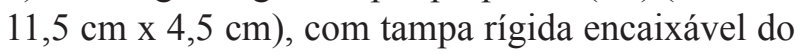
mesmo polímero; 3 ) embalagem flexível (saco plástico) de polipropileno biorientado (BOPP) $(22 \mathrm{~cm} \mathrm{x}$ $15 \mathrm{~cm}$ ), com $0,060 \mathrm{~mm}$ de espessura e taxas de permeabilidade ao $\mathrm{O}_{2}$ e vapor d'água de $63,50 \% \mathrm{~m}^{-2} \mathrm{dia}^{-1}$ e 4,35 $\mathrm{g} \mathrm{m}^{-2} \mathrm{dia}^{-1}$, respectivamente, sob condições normais de temperatura e pressão (temperatura de $23^{\circ} \mathrm{C}$ e pressão de $\left.1 \mathrm{~atm}\right)$.

As embalagens contendo os pimentões minimamente processados foram armazenadas em câmara fria, a $5 \pm 0,1^{\circ} \mathrm{C}$ e umidade relativa de $95 \pm 1 \%$, por 6 dias. As seguintes análises foram realizadas a cada dois dias: 
Perda de massa (\%): utilizando-se balança semianalítica Mettler, modelo PC 2000, e calculando-se a diferença entre a massa inicial das rodelas e a obtida após cada período de avaliação;

Acidez titulável (\% de ácido cítrico): realizada por titulação com hidróxido de sódio a $0,01 \mathrm{M}$, utilizando-se, como indicador, a fenolftaleína (Instituto Adolfo Lutz 1985);

pH: utilizou-se pHmetro TECNAL (Tec 3MP) (AOAC 1992). As avaliações de acidez titulável e pH foram feitas em homogenato filtrado, após trituração das rodelas de pimentão em homogeneizador de tecidos, na proporção 1:4 (rodela:água);

Ácido ascórbico (mg $\left.100 \mathrm{~g} \mathrm{~g}^{-1}\right)$ : extraído com o uso de ácido oxálico $0,5 \%$ e determinado por colorimetria, utilizando-se 2,4 dinitrofenilhidrazina (Strohecker \& Henning 1967);

Valores $\mathrm{L}^{*}$ e $\mathrm{a}^{*}$ : determinados usando-se colorímetro da marca Minolta, modelo CR 400, com iluminante $\mathrm{D}_{65}$, que se expressa pelo sistema de cor CIE L*a*b*. As leituras dos valores $\mathrm{L}^{*} \mathrm{e}$ a* foram feitas em três pontos de cinco rodelas de pimentão, em cada repetição (Minolta 1998);

Firmeza $(\mathrm{N})$ : determinada em três pontos de cinco rodelas de pimentão de cada repetição, com auxílio do texturômetro Stable Micro System modelo TAXT2i, utilizando-se a sonda tipo agulha $\mathrm{P} / 2 \mathrm{~N}$ (2,0 mm de diâmetro), que mediu a força de penetração desta agulha nas rodelas, à velocidade de $5 \mathrm{~mm} \mathrm{~s}^{-1}$, por $5 \mathrm{~mm}$.

O experimento foi conduzido em delineamento inteiramente casualizado, com três repetições. Os tratamentos foram dispostos em esquema fatorial $3 \times 4$, constituído por 3 embalagens e 4 tempos de armazenamento. A parcela experimental foi constituída por uma embalagem contendo cerca de $150 \mathrm{~g}$ de produto minimamente processado. As análises estatísticas foram realizadas com o auxílio do programa Sisvar (Ferreira 2000).

\section{RESULTADOS E DISCUSSÃO}

A perda de massa foi influenciada interativamente pelos fatores embalagem e tempo de armazenamento. A bandeja de poliestireno recoberta com filme de policloreto de vinila (PVC) proporcionou a maior perda de massa, seguida da embalagem de polipropileno (PP) e do saco plástico de polipropileno biorientado (BOPP) (Figura 1). Endo et al. (2006) também relataram desidratação em batatas minima-

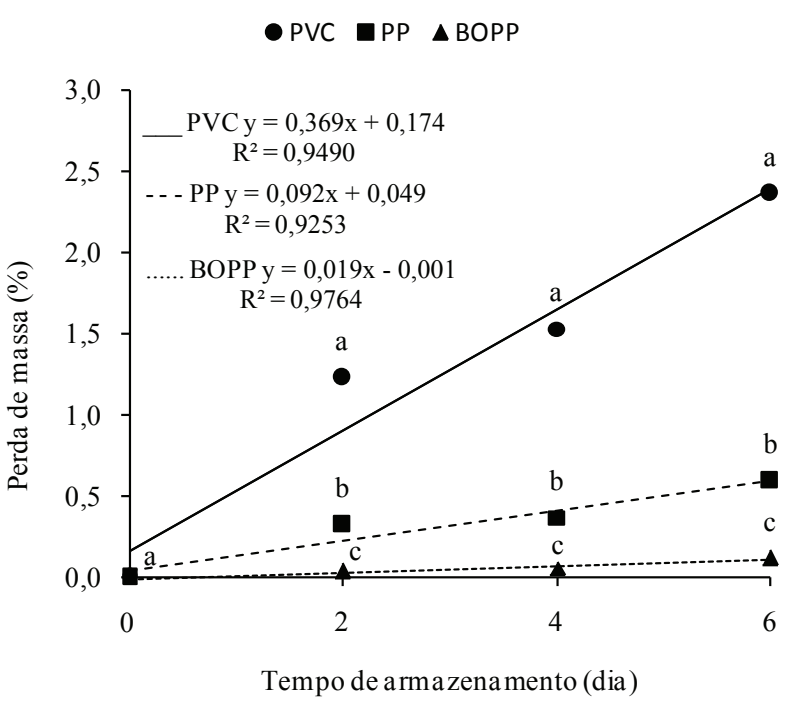

Figura 1. Perda de massa (\%) em pimentão minimamente processado, acondicionado em diferentes embalagens plásticas e armazenado a $5^{\circ} \mathrm{C}$ e $95 \%$ UR (Lavras, MG, 2007). Médias seguidas da mesma letra, dentro de cada tempo, não diferem estatisticamente entre si, pelo Teste Tukey, a 5\%. 1) bandeja de poliestireno expandido recoberta com filme de policloreto de vinila (PVC) $0,014 \mathrm{~mm}$; 2) embalagem rígida de polipropileno (PP), com tampa do mesmo polímero; 3) saco plástico de polipropileno biorientado (BOPP) $0,060 \mathrm{~mm}$.

mente processadas e acondicionadas em bandejas de poliestireno, envoltas com filme de PVC, que tem alta permeabilidade a gases e vapor d'água, o que facilita a desidratação dos produtos acondicionados.

A perda de massa pelos pimentões minimamente processados aumentou linearmente, ao longo do armazenamento, independentemente da embalagem utilizada (Figura 1). As rodelas acondicionadas em bandeja de poliestireno recoberta com filme de PVC apresentaram perda de massa de 2,36\%, no sexto dia de armazenamento, o que também foi observado por Evangelista et al. (2008), em rodelas de pimentão acondicionadas neste tipo de embalagem, com 3,75\% de perda de massa, em 8 dias de armazenamento a $5^{\circ} \mathrm{C}$. A percentagem de perda de massa pelos pimentões minimamente processados acondicionados em embalagem de PP e em saco plástico de BOPP não ultrapassou $0,60 \%$ e $0,12 \%$, respectivamente (Figura 1).

Conforme observado, o controle da perda de massa é importante, pois a grande preocupação, em relação a frutas e hortaliças minimamente processadas, é a manutenção do estado fresco (Cantwell \& 
Suslow 2002). A perda de massa pode comprometer a aparência do produto, levando à perda de frescor, murchamento e enrugamento, quando o produto minimamente processado não é armazenado em condições adequadas de temperatura, umidade relativa e embalagem.

A acidez titulável só foi significativamente afetada pelo fator tempo de armazenamento, com redução em seus teores durante o armazenamento, independentemente da embalagem utilizada (Figura 2), fato que pode estar relacionado ao processo respiratório das rodelas de pimentão, com consumo de ácidos orgânicos, o que também foi observado por Evangelista et al. (2008).

Os valores de $\mathrm{pH}$ das rodelas de pimentão não foram afetados nem pelas embalagens e nem pelo tempo de armazenamento. O mesmo foi observado por Pilon et al. (2006), ao estudar a vida útil de pimentão verde minimamente processado, acondicionado em sacos de polipropileno biorientado/polietileno de baixa densidade, selados sob ar atmosférico, vácuo e atmosfera modificada $\left(2 \% \mathrm{O}_{2}, 10 \% \mathrm{CO}_{2}\right.$ e $88 \%$ $\mathrm{N}_{2}$ ), para o qual não observaram diferenças significativas entre estes tratamentos. Moretti et al. (2000) verificaram que o $\mathrm{pH}$ de pimentão verde, intacto e minimamente processado, não apresentou diferença significativa, indicando que o processamento mínimo não influenciou os valores de $\mathrm{pH}$.

Houve interação significativa entre os fatores embalagem e tempo de armazenamento, para o teor de ácido ascórbico. Os pimentões minimamente processados e acondicionados em bandeja de poliestireno recoberta com filme de PVC apresentaram menores teores de ácido ascórbico, quando comparados com os mantidos em embalagem de $\mathrm{PP}$ e em saco plástico de BOPP, a partir do quarto dia de armazenamento, e nenhuma diferença estatística foi verificada entre estas duas embalagens (Figura 3). Carnelossi et al. (2005) também observaram decréscimo no teor de vitamina $\mathrm{C}$ de quiabo minimamente processado e acondicionado em bandejas de poliestireno recobertas com PVC, quando comparado ao embalado a vácuo, o que pode, provavelmente, estar associado à permeabilidade do filme $\mathrm{PVC}$, em especial ao oxigênio.

O tempo de armazenamento não afetou os teores de ácido ascórbico das rodelas de pimentão acondicionadas nas embalagens de PP e sacos plásticos de BOPP. No entanto, os teores de ácido ascórbico nos pimentões minimamente processados

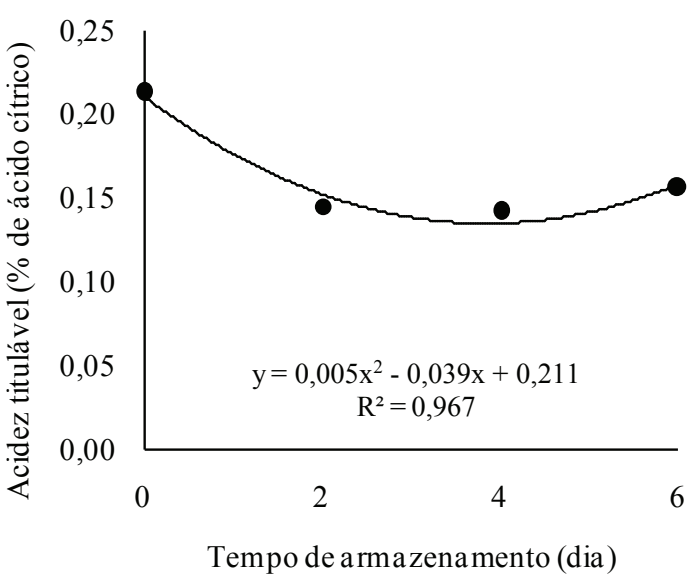

Figura 2. Acidez titulável (\% de ácido cítrico) de pimentão minimamente processado, acondicionado em diferentes embalagens plásticas e armazenado a $5^{\circ} \mathrm{C}$ e $95 \%$ UR (Lavras, MG, 2007).

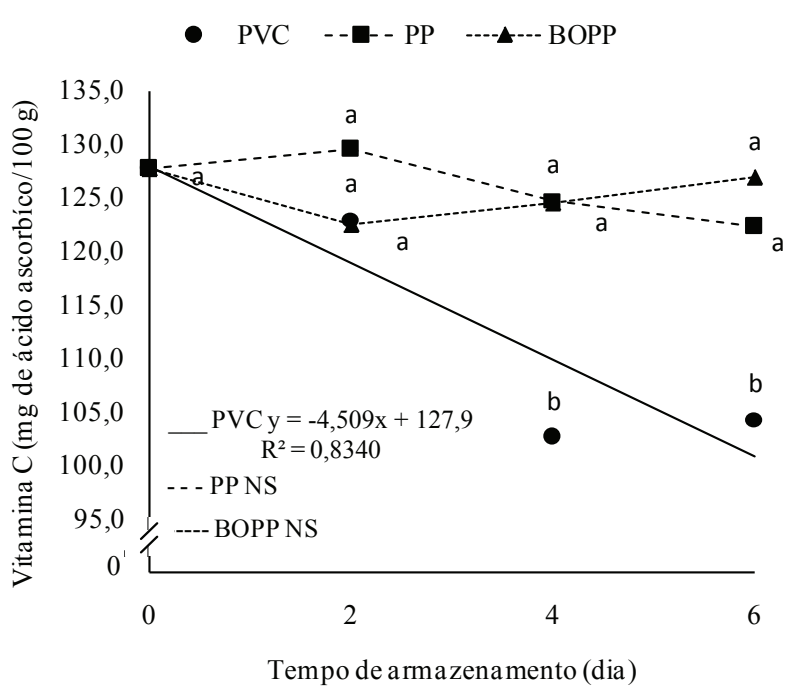

Figura 3. Teor de ácido ascórbico (mg $100 \mathrm{~g}^{-1}$ ) em pimentão minimamente processado, acondicionado em diferentes embalagens plásticas e armazenado a $5^{\circ} \mathrm{C}$ e $95 \%$ UR (Lavras, MG, 2007). Médias seguidas da mesma letra, dentro de cada tempo, não diferem estatisticamente entre si, pelo Teste Tukey, a 5\%. 1) bandeja de poliestireno expandido recoberta com filme de policloreto de vinila (PVC) 0,014 $\mathrm{mm}$; 2) embalagem rígida de polipropileno (PP), com tampa do mesmo polímero; 3 ) saco plástico de polipropileno biorientado (BOPP) 0,060 mm.

e acondicionados em bandeja de poliestireno recoberta com filme de PVC reduziram-se linearmente, ao longo do armazenamento (Figura 3). Pilon et al. (2006) observaram que os teores de ácido ascórbico das rodelas de pimentão verde também reduziram o 
período de armazenamento, mas nenhuma diferença significativa foi verificada entre os sacos plásticos selados sob ar atmosférico, vácuo e atmosfera modificada ativa.

Não houve interação significativa entre os fatores embalagem e tempo de armazenamento, para o valor $\mathrm{L}^{*}$ das rodelas de pimentão, que foi, em média, 37,73, resultado coerente com o encontrado por Hojo et al. (2007), em pimentões armazenados sob películas de fécula de mandioca e PVC, em condições ambiente.

$\mathrm{O}$ valor $\mathrm{a}^{*}$ foi significativamente afetado apenas pelo tempo, observando-se aumento durante o armazenamento (Figura 4), onde a coloração das rodelas de pimentão foi alterada, com redução da cor verde. O mesmo foi observado por Hojo et al. (2007), com o armazenamento de pimentões.

A variável firmeza não foi influenciada significativamente pela interação entre os fatores embalagem e tempo de armazenamento. A firmeza das rodelas de pimentão foi, em média, 1,85 N. Resultado semelhante foi verificado por Hojo et al. (2007), ao avaliarem o uso de películas de fécula de mandioca e PVC na manutenção da qualidade pós-colheita de pimentões armazenados em condições ambiente $\left(22 \pm 1^{\circ} \mathrm{C}\right.$ e $70-98 \%$ UR), com valores médios de firmeza de $1,89 \mathrm{~N}$, para os frutos testemunha.

\section{CONCLUSÃO}

A bandeja de poliestireno envolta com filme PVC determina maior perda de massa e menor teor

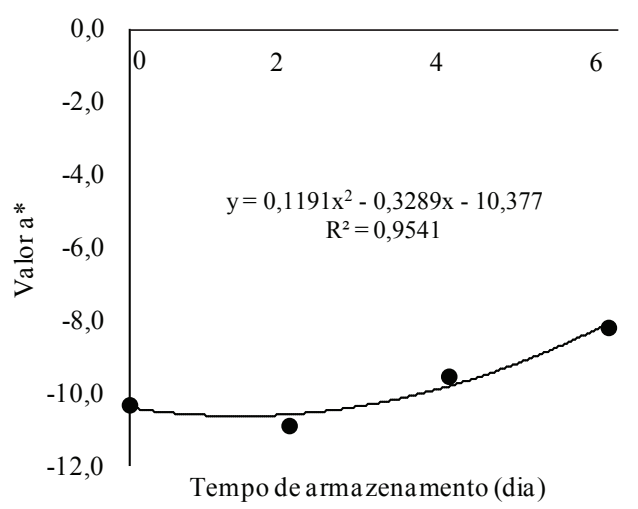

Figura 4. Variação no valor a* da coloração de pimentão minimamente processado, acondicionado em diferentes embalagens plásticas e armazenado a $5^{\circ} \mathrm{C}$ e $95 \%$ UR (Lavras, MG, 2007). de ácido ascórbico, em rodelas de pimentão verde armazenadas a $5^{\circ} \mathrm{C}$, por 6 dias. Assim, a embalagem rígida de $\mathrm{PP}$ e o saco plástico de $\mathrm{BOPP}$ são preferíveis para acondicionar o pimentão verde minimamente processado.

\section{AGRADECIMENTOS}

\begin{abstract}
Ao Conselho Nacional de Desenvolvimento
Científico e Tecnológico (CNPq), pelo apoio financeiro à realização deste trabalho.
\end{abstract}

\section{REFERÊNCIAS}

ALBUQUERQUE, K. S. et al. Condicionamento osmótico e giberelina na qualidade fisiológica de sementes de pimentão colhidas em diferentes estádios de maturação. Revista Brasileira de Sementes, Londrina, v. 31, n. 4, p. 100-109, 2009.

ASSOCIATION OF OFFICIAL ANALYTICAL CHEMISTRY (AOAC). Official methods of analysis of the Association of Official Analytical Chemistry. 12. ed. Washington, DC: AOAC, 1992.

CANTWELL, M. I.; SUSLOW, T. V. Postharvest handling systems: fresh-cut fruits and vegetables. In: KADER, A. A. (Ed.). Postharvest technology of horticultural crops. 3. ed. Davis: University of California Agriculture \& Natural Resources, 2002. p. 445-463.

CARNELOSSI, M. A. G. et al. Determinação das etapas do processamento mínimo de quiabo. Horticultura Brasileira, Brasília, DF, v. 23, n. 4, p. 970-975, 2005.

ENDO, E. et al. Alterações físicas e físico-químicas de batatas (Solanum tuberosum L.) minimamente processadas intercaladas com diferentes filmes ativos. Alimentos $e$ Nutrição, Araraquara, v. 17, n. 3, p. 239-249, 2006.

EVANGELISTA, R. M. et al. Qualidade de pimentão 'Rúbia' minimamente processado e armazenado sob refrigeração. Revista Ceres, Viçosa, v. 55, n. 4, p. 338343, 2008.

FERREIRA, D. F. Análises estatísticas por meio do SISVAR para Windows versão 4.0. In: REUNIÃO ANUAL DA REGIÃO BRASILEIRA DA SOCIEDADE INTERNACIONAL DE BIOMETRIA, 45., 2000, São Carlos. Programa e resumos... São Carlos: UFSCar, 2000. p. 235 .

FILGUEIRA, F. A. R. Novo manual de olericultura: agrotecnologia moderna na produção e comercialização de hortaliças. 3. ed. rev. e ampl. Viçosa: UFV, 2007. 
HOJO, E. T. D. et al. Uso de películas de fécula de mandioca e PVC na conservação pós-colheita de pimentão. Ciência e Agrotecnologia, Lavras, v. 31, n. 1, p. 184-190, 2007.

INSTITUTO ADOLFO LUTZ. Normas analíticas, métodos químicos e físicos para análise de alimentos. 3. ed. São Paulo: Instituto Adolfo Lutz, 1985.

LANA, M. M. et al. Pimentão. Brasília, DF: Embrapa Hortaliças, 2011.

LUENGO, R. de F. A. et al. Tabela de composição nutricional das hortaliças. Brasília, DF: Embrapa Hortaliças, 2000. (Documentos, 26).

MAIA, G. E. G. et al. Determinação dos teores de vitamina $\mathrm{C}$ em hortaliças minimamente processadas. Alimentos $e$ Nutrição, Araraquara, v. 19, n. 3, p. 329-335, 2008.

MINOLTA. Precise color communication: color control from perception to instrumentation. Sakai: Minolta, 1998.

MORETTI, C. L. Panorama do processamento mínimo de frutas e hortaliças. In: MORETTI, C. L. (Ed.). Manual de processamento mínimo de frutas e hortaliças. 2. ed. Brasília, DF: Embrapa Hortaliças/Sebrae, 2007. p. 25-40.

MORETTI, C. L.; PUSCHMANN, R. Processamento mínimo de hortaliças. In: ENCONTRO NACIONAL SOBRE PROCESSAMENTO MÍNIMO DE FRUTAS E HORTALIÇAS; SIMPÓSIO ÍBEROAMERICANO DE VEGETAIS FRESCOS CORTADOS, 4., 2006, São Pedro. Palestras, resumos, fluxogramas e oficinas... Piracicaba: USP/ESALQ/CYTED, 2006. p. 234-239.
MORETTI, C. L.; SILVA, W. L. C.; ARAÚJO, A. L. Quality attributes and carbon dioxide evolution of bell peppers as affected by minimal processing and storage temperature. Proceedings of the Florida State Horticultural Society, Orlando, v. 113, n. 1, p. 295-296, 2000.

ÖZKAN, M.; AYSEGÜL, K.; CEMEROGLU, B. Effects of hydrogen peroxide on the stability of ascorbic acid during storage in various fruit juices. Food Chemistry, Oxford, v. 88, n. 4, p. 591-597, 2004.

PILON, L. et al. Shelf life of minimally processed carrot and green pepper. Ciência e Tecnologia de Alimentos, Campinas, v. 26, n. 1, p. 150-158, 2006.

SOARES, N. F. F.; GERALDINE, R. M. Embalagens. In: MORETTI, C. L. (Ed.). Manual de processamento mínimo de frutas e hortaliças. Brasília, DF: Embrapa Hortaliças, 2007. p. 153-171.

STROHECKER, R.; HENNING, H. M. Analisis de vitaminas: metodos comprobados. Madrid: Paz Montalvo, 1967. 